\title{
ATIVIDADE ATPÁSICA E PIROFOSFATÁSICA EM MICROSSOMOS DE RAÍZES DE MILHO COLONIZADAS COM FUNGOS MICORRÍZICOS ARBUSCULARES ${ }^{(\mathbf{1})}$
}

\author{
Alessandro Coutinho Ramos(2), Marco Antônio \\ Martins $^{(3)}$ \& Arnoldo Rocha Façanha ${ }^{(4)}$
}

\begin{abstract}
RESUMO
No presente trabalho, foi avaliada a influência de duas espécies de fungos mi corrízicos arbusculares (F MAs) Glomus clarum e Gigaspora margarita sobre as atividades ATPásica e pirofosfatásica de microssomos obtidos por meio de fracionamento celular de raízes de mi lho colonizadas aos 20,30, 40 e 60 dias do plantio. Ambos os fungos proporcionaram aumentos si gnificativos nas atividades das ATPases e pirofosfatases; entretanto, as maiores atividades foram observadas nas raízes colonizadas pelo fungo $\mathrm{G}$. clarum. Os dados cinéticos indicaram a presença de uma ativação diferencial das $\mathrm{H}^{+}$-ATPases e $\mathrm{H}^{+}$-pirofosfatases presentes nas membranas das células radiculares, dependendo da espécie fúngica e do estádio da colonização das raízes pelos FMAs. Como indicadores da eficiência da micorrização, foram avaliados a altura e o conteúdo de nutrientes na parte aérea das plantas. Os dados obtidos mostraram a primeira evidência cinética de estimulação de ativi dade pi rofosfatásica em membranas microssomais de raízes colonizadas e descreveram um padrão inédito de ativação diferencial para a hidrólise de ATP, dependendo da espécie (G. clarum ou G. margarita) e do estádio de colonização.
\end{abstract}

Termos de indexação: micorriza arbuscular, $\mathbf{H}^{+}$-ATPase, $\mathbf{H}^{+}$-PPase, Glomus clarum, Gigaspora margarita.

(1) Recebido para publicação em setembro de 2003 e aprovado em dezembro de 2004.

(2) Doutorando, U niversidade Estadual do Norte Fluminense Darcy Ribeiro- UE NF. Centro de Ciências eTecnol ogias Agropecuárias, Laboratório de Solos. Av. Alberto Lamego 2000, CEP 28015-620 Campos dos Goytacazes (RJ ). E-mail: coutinho@uenf.br.

(3) Professor Associado, Centro de Ciências e Tecnologias Agropecuárias, Laboratório de Solos, UENF. Bolsista do CNPq. E-mail: marco@uenf.br.

(4) Professor Associado, Centro de Biotecnologia e Biociências, Laboratório de Biologia Celular e Tecidual, UENF. E-mail: arnoldo@uenf.br 


\title{
SUMMARY: ATPASE AND PYROPHOSPHATASE ACTIVITIES IN CORN ROOT MICROSOMES COLONIZED WITH ARBUSCULAR MYCORRHIZAL FUNGI
}

\begin{abstract}
Theinfluenceof two species of arbuscular mycorrhizal fungi (AMF) on theATPaseand pyrophosphatase activities of corn root microsomes was investigated at 20,30,40, and 60 days after planting. The microsomes were isolated by cell fractionation from corn roots colonized with Glomus clarum or Gigaspora margarita. Both fungi led to a significant increase in the ATPase and pyrophosphatase activities though the highest activities were observed in roots colonized with $\mathrm{G}$. clarum. Kinetics analysis suggested that mycorrhizal colonization promoted a differential regulation of the $\mathrm{H}^{+}-$ATPases and $\mathrm{H}^{+}$-PPases present in the root cell membranes. This regulation varied according to the fungal species and stage of AMF root col onization. Height and nutrient content of theplant shoot wereanalyzed as parameters of mycorrhization efficiency. The obtained data present the first evidence based on the kinetics of activation of pyrophosphatases in microsomal membranes from col onized roots, and describea novel pattern for thedifferential activation of ATP hydrolysis depending on the fungal species (G. clarum or G. margarita) and colonization stage.
\end{abstract}

Index terms: arbuscular mycorrhiza, $\mathrm{H}^{+}$-ATPase, $\mathrm{H}^{+}$-PPase, Glomus clarum, Gigaspora margarita.

\section{NTRODUÇÃO}

Na associação micorrízica arbuscular, a planta hospedeira supre o fungo com açúcares derivados do processo de fotossíntesee, em troca, esteaumenta a capacidade da planta em absorver água e vários nutrientes do solo (Smith \& Read, 1997). Estudos citoquímicos têm mostrado que, na simbiose micorrízica, um movimento bidirecional de íons opera na interface fungo-planta, sugerindo a presença de sistemas especializados de transporte ativo na membrana periarbuscular (Marx et al., 1982; Gianinazzi-Pearson et al., 1991; GianinazziPearson, 1996). Tantoem plantas quanto em fungos, a absorção de nutrientes ocorre, principal mente, via transportadores específicos encontrados nas membranas de células de raízes e hifas. Estes transportadores secundários necessitam de um aporte de energia que é fornecido pelos sistemas de transporte primários, constituídos, essencialmente, pelas bombas de prótons que nas plantas incluem vários tipos de $\mathrm{H}^{+}$-ATPases (Morsomme \& Boutry, 2000) e uma $\mathrm{H}^{+}$-pirofosfatase (Rea et al., 1992).

A fração microssomal, obtida por fracionamento celular de tecidos vegetais, é constituída principalmente por vesículas de membranas oriundas da plasmalema e do tonoplasto, e as principais enzimas responsáveis pela catálise da hidrólise de ATP são as $\mathrm{H}^{+}$-ATPases do tipo $\mathrm{P}$ e V presentes nestas membranas (Sze, 1985). Em membranas microssomais, observa-se a hidrólise de pirofosfato $\left(\mathrm{PP}_{\mathrm{i}}\right)$ a qual é catalisada por uma pirofosfatase translocadora de prótons ( $\mathrm{H}^{+}-\mathrm{PP}$ ase), que atua em paralelo com a V-ATPase presente no tonoplasto (Rea et al., 1992). Nas plantas, em diversas condições fisiológicas e de estresse, o pirofosfato pode assumir o papel do ATP, atuando como doador de energia metabólica da célula (Stitt, 1998). No tonoplasto, a $\mathrm{H}^{+}$-PPase é funcional na energização dos sistemas de transporte secundários da membrana vacuolar, atuando também no controle da homeostase citoplasmática, em sincronismo com a V-ATPase de tonoplasto e com a $\mathrm{H}^{+}$-ATPase de plasmalema (Rea et al., 1992; Sze et al., 1999).

Estudos com sondas indicadoras de $\mathrm{pH}$ demonstraram quea matriz periarbuscular consiste num compartimento ácido, corroborando a hipótese da presença de bombas de prótons ativas na interface simbiótica (Guttenberger, 2000). Murphy et al. (1997) isolaram um fragmento de CDNA de $\mathrm{H}^{+}$ ATPases de plantas de cevada, o qual mostrou uma alta acumulação de transcritos em raízes inoculadas, quando comparado às das não inoculadas com F MA. Posteriormente, Gianinazzi-Pearson et al. (2000) detectaram quea micorrização provocou a atividade de promotores relacionados com dois genes codificares para duas isoformas de $\mathrm{H}^{+}$-ATPases (pma2 e pma4) em células corticais de raízes de tabaco que continham arbúsculos. Krajinski et al. (2002) revelaram a presença de um gene de $\mathrm{H}^{+}$ ATPases de plasmalema tecido-específico em Medicago truncatula (Mtha1), o qual é expresso apenas em células radiculares com arbúsculos. Entretanto, dados bioquímicos, quanto à regulação dessa atividade nas membranas celulares de raízes micorrizadas, ainda são escassos e, por vezes, conflitantes (McArthur \& Knowles, 1993; Bago et al., 1997; Benabdellah et al., 1999).

Este trabalho teve como objetivo investigar a participação dos sistemas primários de transporte 
de prótons microssomais no desenvolvimento e estabelecimento da colonização de raízes de milho pel os F MAs Glomus clarum eGigaspora margarita.

\section{MATERIAL E MÉTODOS}

Realizou-se um experimento em casa de vegetação em delineamento inteiramente casualizado e esquema fatorial $3 \times 4$, constando de três tratamentos de inoculação (não inoculado - C, inoculado com G. clarum (Nicolson \& Schenk)- Gc ou G. margarita (Becker \& Hall) - Gm) e quatro épocas de coleta (20, 30, 40 e 60 dias após inoculação), com cinco repetições. Escol heram-se estes isolados fúngi cos, por tratar-se de FMAs diferentes em gênero e características morfológicas, tanto do desenvolvimento assimbiótico quanto do simbiótico. Coletaram-se amostras de um solo argiloso, classificado como Cambissolo, da região de Campos dos Goytacazes (RJ ), que foram secas ao ar, destorroadas e passadas em peneira de $2 \mathrm{~mm}$. O substrato foi composto de areia e o solo argiloso, na proporção 2:1 (VN). Depois de preparado, o substrato foi esterilizado, autoclavando-o a $121{ }^{\circ} \mathrm{C}$ por $2 \mathrm{~h}$. A análise química do substrato revelou as seguintes características: $\mathrm{pH}$ em $\mathrm{H}_{2} \mathrm{O}=5$,5; $\mathrm{P}$ (Mehlich-1) $=9 \mathrm{mg} \mathrm{dm}^{-3} ; \mathrm{K}=$ $148 \mathrm{mg} \mathrm{dm}^{-3} ; \mathrm{Ca}=20 \mathrm{mmol}_{\mathrm{c}} \mathrm{dm}^{-3} ; \mathrm{Mg}=$ $13 \mathrm{mmol}_{\mathrm{C}} \mathrm{dm}^{-3} ; \mathrm{Al}=0,0 \mathrm{mmol}_{\mathrm{C}} \mathrm{dm}^{-3}$.

As sementes de milho (híbrido UENF 506-6) foram obtidas do banco de germoplasma do Laboratório de Melhoramento Genético Vegetal da UENF. A inoculação das plantas com os dois FMAs, Glomus clarum ou Gigaspora margarita, foi realizada no plantio, aplicando-se $100 \mathrm{~g}$ do inóculo a $3 \mathrm{~cm}$ abaixo da superfície do substrato (constituído por uma mistura de solo, hifas, esporos e raízes). O inóculo foi preparado em vasos de cultivo com Brachiaria decumbens stapf. como planta multiplicadora dos FMAs. O tratamento não inoculado recebeu a mesma mistura, porém previamente autoclavada. Semearam-se oito sementes por vaso $(2,5 \mathrm{~L})$ e, 10 dias após a germinação, fez-se um desbaste, deixando apenas quatro plantas por vaso.

Aos 20, 30, 40 e 60 dias, foram avaliadas a taxa de col onização micorrízica das raízes de milho e as atividades enzimáticas na fração microssomal. Aos 60 dias, analisaram-seo crescimento ea concentração de nutrientes na parte aérea. A taxa de col onização micorrízica foi determinada pelo método da interseção em placas de Petri reticuladas, como descrito por Giovannetti \& Mosse (1980), após coloração com azul de metileno, conforme técnica descrita por Phillips \& Hayman (1970).

A fração microssomal de raízes de milho foi preparada por centrifugação diferencial, como descrito por DeMichelis \& Spanswick (1986) com modi ficações de Façanha \& de Meis (1995). As amostras de tecidos frescos de raízes (25-50 g) foram homogeneizadas em meio tamponado que continha: Sacarose $250 \mathrm{mmol} \mathrm{L}^{-1}$, Glicerol $10 \%$, DTT $2 \mathrm{mmol} \mathrm{L}^{-1}$, EDTA $5 \mathrm{mmol} \mathrm{L}-1, \mathrm{PVP}-400,5 \%, \mathrm{KCl} 150 \mathrm{mmol} \mathrm{L}^{-1}, \mathrm{BSA}$ $0,13 \%$, PMSF $2 \mathrm{mmol} \mathrm{L}^{-1}$, Tris- $\mathrm{HCl}(\mathrm{pH} \mathrm{8,0)}$ $0,1 \mathrm{mmol} \mathrm{L}^{-1}$. O homogenato foi filtrado e centrifugado $1.000 \times$ g por $15 \mathrm{~min}$. O sobrenadante foi submetido a uma nova centrifugação a $10.000 \times \mathrm{g}$ por $20 \mathrm{~min}$, descartando-se, em seguida, o precipitado composto principalmente de mitocôndrias e peroxissomos, possibilitando uma separação microssomal mais limpa deproteínas contaminantes, visando auxiliar na revel ação da ativação específica das ATPases microssomais. O sobrenadante desta última centrifugação foi submetido a uma ultracentrifugação a 100.000 x g por 30 min, obtendo-se um precipitado correspondemente à fração microssomal, o qual foi ressuspenso em $1 \mathrm{~mL}$ de soIução com: Glicerol $15 \%$, DTT 1 mmol L-1, PMSF $1 \mathrm{mmol} \mathrm{L}-1$, HEPS-KOH $10 \mathrm{mmol} \mathrm{L}^{-1}(\mathrm{pH} 7,6) \mathrm{e}$ EDTA $1 \mathrm{mmol} \mathrm{L}^{-1}$. A dosagem de proteína foi efetuada pel o método de Lowry et al. (1951).

A atividade ATPásica foi determinada como descrito por Fiske \& Subbarrow (1925) por meio da dosagem colorimétrica de fosfato inorgânico $\left(P_{i}\right)$ liberado durante a hidrólise enzimática de ATP ou $\mathrm{PP}_{\mathrm{i}}$. O meio de reação consistiu de: MOPS-Tris $\mathrm{pH} 6,550 \mathrm{mmol} \mathrm{L}-1 ; \mathrm{MgCl}_{2} 5 \mathrm{mmol} \mathrm{L}^{-1}, \mathrm{KCl}$ $100 \mathrm{mmol} \mathrm{L}^{-1}$, ATP $1 \mathrm{mmol} \mathrm{L}^{-1}$ e $0,03 \mathrm{mg} \mathrm{mL}^{-1}$ de proteína microssomal. Para atividade pi rofosfatásica, procedeu-se somente substituição do tampão que passou a ser MOPS-Tris pH 7,0 e o substrato $\mathrm{PP}_{\mathrm{i}}$ $0,1 \mathrm{mmol} \mathrm{L}^{-1}$.

Os nutrientes da parte aérea foram analisados somente 60 dias após o plantio. Os teores de N, P, $\mathrm{K}$, Ca e Mg na parte aérea foram determinados depois que as amostras foram desidratadas em estufa de ventilação forçada, a uma temperatura de cerca de $75^{\circ} \mathrm{C}$, por $48 \mathrm{~h}$ (Malavolta et al., 1989). Uma vez desidratado, o material foi pesado para determinação da matéria seca e, em seguida, as amostras foram moídas em moinho tipo Willey, passadas em peneira de 20 mesh earmazenadas em frascos hermeticamente fechados. Após submeter 0 material vegetal à oxidação pela digestão sulfúrica, foram determinados: o $\mathrm{P}$ por colorimetria, pelo método do molibidato (Malavol ta et al., 1989), o N, pelo método de Nessler (J ackson, 1965); o K, por espectrofotometria de emissão de chama, e o Ca e o $\mathrm{Mg}$, por espectrofotometria de absorção atômica, de acordo com os métodos do Manual de Análises de Solo e Plantas (E mbrapa, 1997).

Os dados foram submetidos à análise de variância, utilizando o nível de significância de 5 \%. Os valores relativos à percentagem de colonização micorrízica no sistema radicular foram transformados para arc sem $\sqrt{\mathrm{x} / 100}$, e as médias foram comparadas pelo teste Tukey por meio do programa SAEG-UFV. 


\section{RESULTADOS E DISCUSSÃO}

A percentagem de colonização das raízes de milho foi significativamente maior no tratamento inoculado com o fungo $\mathrm{Gc}$, em comparação com $\mathrm{Gm}$ (Figura 1). Não foi observada colonização micorrízica nas raízes das plantas controle (não inoculado). Ambos os tratamentos inoculados com Gc e Gm apresentaram atividade ATPásica estatisticamente superior à do tratamento não inoculado, exceto aos 20 dias no tratamento inoculado com a espécie Gm (Figura 2a).

A pesar de existirem al guns relatos anteriores de ativação de $\mathrm{H}^{+}$-ATPases associada a microssomos de raízes mi corrizadas (M cArthur \& Knowles, 1993; Bago et al., 1997; Benabdellah et al., 1999), tal ativação foi observada somente quando as atividades específicas foram calculadas com base na matéria fresca de raiz micorrizada. Entretanto, estudos citoquímicos (Marx et al., 1982; Gianinazzi-Pearson et al., 1991) indicam quea contribuição das ATPases fúngicas e, ou, arbusculares parece ser bem mais significativa em relação ao conteúdototal de proteína da raiz micorrizada do que a contribuição da massa do fungo intra-radicular em comparação com a massa vegetal para a massa fresca total da raiz micorrizada. Assim, a estimulação da atividade ATPásica obtida somente com base no peso fresco de raiz poderia consistir somente num somatório das atividades ATPásicas das membranas do fungo e da

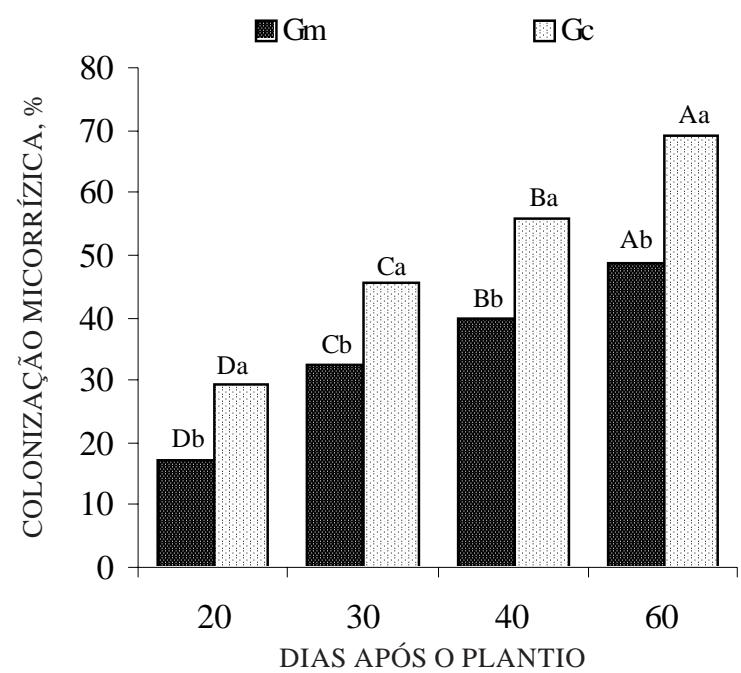

Figura 1. Colonização micorrízica em raízes de milho, inoculadas com FMAs: Gigaspora margarita (Gm) ou Glomus clarum (Gc) aos 20, 30, 40 e 60 dias do plantio. Médias seguidas de mesma letra não diferem entre si pelo teste Tukey a $5 \%$. As barras com letras maiúsculas comparam as médias entre as épocas avaliadas num mesmo FMA, e as com minúsculas comparam médias entre os F MAs numa mesma época. planta exacerbado pela divisão pelo peso do tecido fresco, representado quase exclusivamente pela massa do tecido vegetal. De fato, nos estudos anteriores, o estímulo desaparecia quando a atividade era calculada com base no conteúdo de proteína total o qual também cresce com a micorrização. Nas condições experimentais deste estudo, conseguiu-se evidenciar a estimulação mesmo quando calculada com base na proteína, o que pode representar um enriquecimento das ATPases em relação às demais proteínas presentes nos microssomos (F igura 2a).

A estimulação da atividade ATPásica verificada no presente estudo (F igura 2a) está em concordância com dados moleculares que relatam a capacidade do FMA em induzir a expressão de genes de $\mathrm{H}^{+}$ ATPases de membrana plasmática da planta hospedeira (Murphy et al., 1997; Gianinazzi-Pearson et al., 2000), mais especificamente identificada na membrana periarbuscular (Krajinski et al., 2002). A menor taxa de estimulação da atividadeATPásica 20 dias após o plantio pode estar correlacionada com o fato de que, neste estádio inicial da col onização, a área da raiz que apresenta arbúsculos é muito incipiente, comparada à ocorrência verificada aos 60 dias, estádio no qual tem si do observada a maior proliferação de arbúsculos na cultura do milho col onizada com F MAs do gênero Glomus (Alexander et al., 1989; Toth et al., 1990).

Aos 40 e 60 dias, foram observadas as maiores taxas de colonização (Figura 1); todavia, após 30 dias, a taxa colonização passou a crescer num ritmo mais lento, indicando o início da estabilização da colonização micorrízica, principalmente no caso da espécie Gm. No mesmo estádio, observou-se a estabilização da atividadeATPásica que cresceu até os 30 dias, mas manteve praticamenteo mesmo nível de atividade aos 40 e 60 dias (Figura 2a). Verificouse, ainda, quea col onização com Gc promoveu maior estimulação da atividade ATPásica em relação àquela promovida por Gm (Figura 2a). Este dado poder efletir as diferenças bioquímicas efisiológicas no hospedeiro com a inoculação de espécies pertencentes a gêneros diferentes.

Além da ativação da hidrólise de ATP, as vesículas microssomais isoladas de plantas inoculadas com ambos os FMAs estudados exibiram um padrão peculiar einédito de ativação da hidrólise de pirofosfato $\left(\mathrm{PP}_{\mathrm{i}}\right)$ associado a estas membranas. Em sistemas vegetais, o $\mathrm{PP}_{\mathrm{i}}$ tem sido considerado um substrato alternativo ao ATP, podendo ativar o metabolismo em condições de estresse energético, quando ocorre a depleção dos níveis de ATP citossólico (Stitt, 1998). O consumo da sacarose radicular pelo FMA pode causar um estresse energético transiente nas células da raiz (Smith \& Read, 1997), especialmente nos estádios iniciais da colonização, quando o equilíbrio da troca de nutrientes entre os simbiontes ainda não foi 


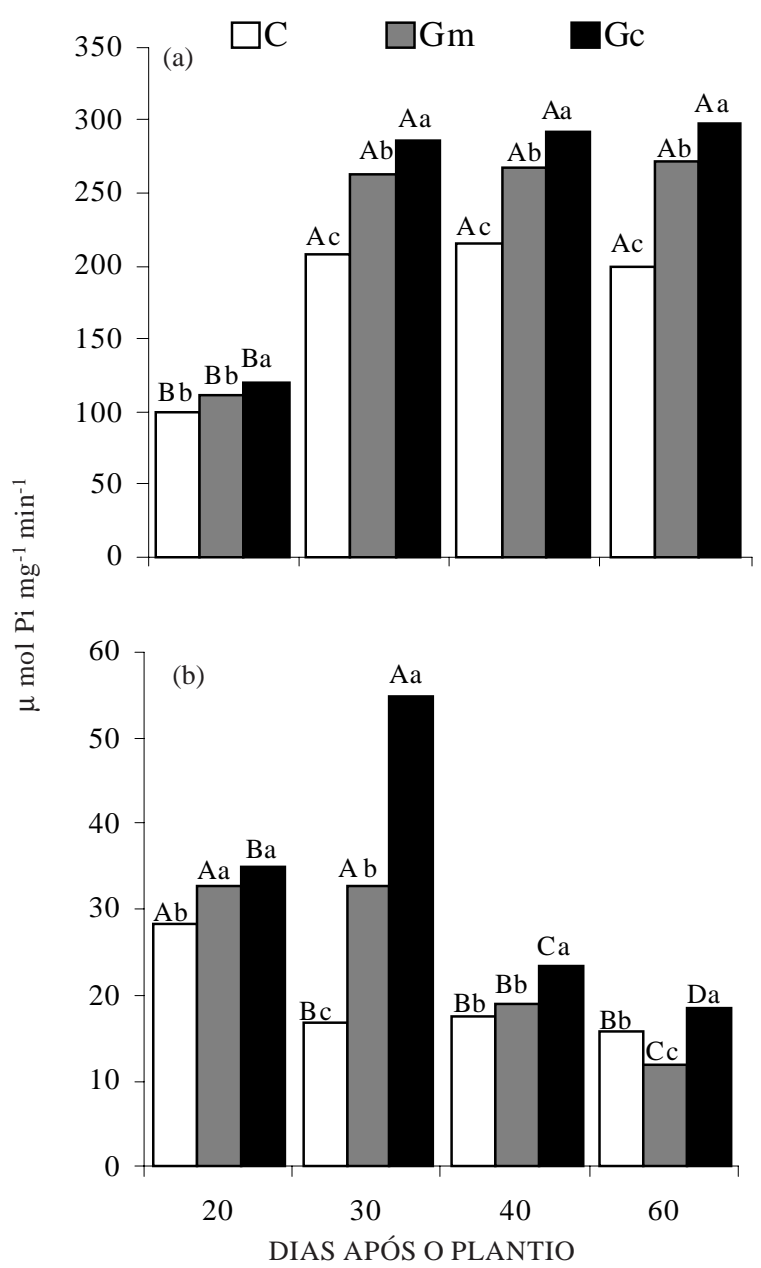

Figura 2. Atividade ATPásica (A) e Pirofosfatásica (B) em microssomos de raízes de milho não inoculadas (Controle, C) ou inoculadas com Gigaspora margarita (Gm) ou Glomus clarum (Gc) aos 20, 30, 40 e 60 dias do plantio. As atividades enzi máticas são expressas em ìmoles de Pi liberado por mg de proteína microssomal e por minuto de reação. Médias seguidas de mesma letra não diferem entre si pelo teste Tukey a $5 \%$. As barras com letras maiúsculas comparam as médias entre as épocas avaliadas num mesmo FMA, e as com minúsculas comparam médias entre os FMAs numa mesma época.

estabelecido. Desde que a $\mathrm{H}^{+}$-PPase vacuolar é a principal enzima capaz de hidrolisar $\mathrm{PP}_{\mathrm{i}}$ presente nas membranas microssomais, o estímulo observado deve estar relacionado com a ativação desta enzima induzida pela micorrização.

Uma hipótese recente descreve um possível acoplamento entre as duas bombas de prótons vacuolares, onde o gradiente eletroquímico gerado pela $\mathrm{H}^{+}$-PPase energizaria a reversão do ciclo catalítico da $\mathrm{H}^{+}$-ATPase, favorecendo a síntese de ATP (Façanha \& de Meis, 1998). Assim, a indução deste sistema regenerador de ATP durante a interação micorrízica pode ser parte da resposta adaptativa da planta ao estresse decorrente do consumo da sacarose radicular pelo FMA. De fato, é bem conhecido que, nos estádios iniciais do estabel ecimento da colonização mi corrízica, geralmente ocorre uma inibição do crescimento da planta (Smith \& Read, 1997; Williams et al., 1987), o que também pode ser relacionado com o estresse inicial, causado pela colonização do FMA na raiz hospedeira, e com o consumo de carbono fotossintetizado pela planta antes que essa venha a usufruir os benefícios da associação micorrízica.

Microssomas de raízes col onizadas com Gc apresentaram uma marcante estimulação da atividade pirofosfatásica aos $30 \mathrm{DAP}$, aproximadamente três vezes superior ao controle (Figura 2b). Dada a característica de formação de vesículas ser inerente a fungos da gênero Glomus, estes poderiam drenar mais carbono da planta hospedeira durante o estabelecimento da interação simbiótica para a produção e manutenção da biomassa fúngica (Graham \& Eissenst, 1994). E m resposta a essa condição, é possível que este maior aumento na hidrólise $\mathrm{PP}_{\mathrm{i}}$ verificado nos microssomas de raízes colonizadas com Gc (Figura 2b) possa refletir o estado energético das células radiculares exauridas de carbono pel o FMA.

$\mathrm{O}$ desempenho inferior de $\mathrm{Gm}$, no que tange à ativação das ATPases e PPases, pode estar relacionado com características da espécie que não forma vesículas e apresenta um tipo de colonização anatomicamente diferente de Gc, com hifas intercelulares mais esparsas e com uma menor freqüência de arbúsculos (Smith \& Read, 1997). Dada a importância dessas estruturas no processo de troca bidirecional e na ativação de genes relacionados com à $\mathrm{H}^{+}$-ATPases de células corticais (Murphy et al., 1997; Gianinazzi-Pearson et al., 2000), pode-se esperar que o $\mathrm{Gm}$ seja menos efetivo em desencadear respostas na atividadedas ATPases ePPases. Plantas inoculadas com Gc apresentaram concentrações de nutrientes (exceto $N$ ) e medidas decrescimento (exceto matéria fresca da parteaérea) superiores àquelas inoculadas com Gm que, todavia, apresentaram valores superiores aos obtidos com plantas não inoculadas, com exceção no conteúdo de Ca e matéria fresca da parte aérea (Quadro 1).

O quadro 1 mostra o incremento nos teores deK, $\mathrm{N}, \mathrm{Ca}$ e Mg nas plantas inoculadas, comprovando o estabelecimento funcional de ambos os FMAs aos $60 \mathrm{DAP}$. No caso específico do $\mathrm{K}^{+}$e do $\mathrm{Mg}^{2+}$ estes são conhecidos ativadores alostéricos das $\mathrm{H}^{+-}$ ATPases e da $\mathrm{H}^{+}$-PPase (Sze et al., 1999). Adicional mente, $\mathrm{OMg}^{2+}$ pode exercer um papel ainda mais fundamental na ativação induzida pela micorrização, desde que os complexos MgATP e $\mathrm{MgPP}_{\mathrm{i}}$ sejam os verdadei ros substratos das bombas de prótons das membranas microssomais.

Observa-se uma correl ação positiva esignificativa entre a taxa de colonização micorrízica (COL) e 
Quadro 1. Conteúdo de nutrientes na parte aérea e medidas de crescimento das plantas de milho aos 60 dias do plantio. Tratamento não inoculado (C) ou inoculado com Gigaspora margarita (Gm) ou Glomus clarum (Gc)

\begin{tabular}{|c|c|c|c|c|c|c|c|c|}
\hline \multirow{2}{*}{ Tratamento } & \multicolumn{5}{|c|}{ Nutriente } & \multirow{2}{*}{ MFR } & \multirow{2}{*}{ MFPA } & \multirow{2}{*}{ Altura } \\
\hline & $\mathbf{N}$ & $\mathbf{P}$ & $\mathbf{K}$ & $\mathrm{Ca}$ & $\mathbf{M g}$ & & & \\
\hline & \multicolumn{5}{|c|}{ - mg planta-1 } & \multicolumn{2}{|c|}{ g planta-1 } & $\mathrm{cm}$ \\
\hline $\mathrm{C}$ & $35,44 \mathrm{~b}$ & $3,93 \mathrm{c}$ & $71,60 \mathrm{c}$ & $11,45 \mathrm{~b}$ & $10,74 \mathrm{c}$ & $7,94 \mathrm{c}$ & $17,08 \mathrm{~b}$ & $85,50 \mathrm{c}$ \\
\hline $\mathrm{Gm}$ & $42,42 \mathrm{a}$ & $4,84 \mathrm{~b}$ & $95,34 b$ & $12,92 \mathrm{~b}$ & $15,35 \mathrm{~b}$ & $10,32 b$ & $18,43 a b$ & 93,16 b \\
\hline $\mathrm{Gc}$ & $45,79 a$ & $7,15 \mathrm{a}$ & $15,35 a$ & $24,80 a$ & $22,41 \mathrm{a}$ & $14,12 \mathrm{a}$ & 20,58 a & $110,5 \mathrm{a}$ \\
\hline
\end{tabular}

MFR - Matéria fresca de raiz; MFPA - Matéria fresca de parte aérea.

Médias seguidas por uma mesma letra, numa mesma coluna, não diferem entre si, pelo teste Tukey a $5 \%$.

Quadro 2. Coeficientes de correlação de Pearson ( $n=48$ observações) entre as atividades ATPásica e pirofosfatásica total, taxa de colonização micorrízica (COL) das raízes de milho (Zea mays L.) inoculadas com duas espécies de fungos micorrízicos arbusculares (Gigaspora margarita ou Glomus clarum)

\begin{tabular}{llll}
\hline & ATPásica & PPásica & COL \\
\hline ATPásica & 1,0000 & $-0,1998^{\mathrm{ns}}$ & $0,8233^{*}$ \\
PPásica & - & 1,0000 & $-0,3306^{\mathrm{ns}}$ \\
COL & - & - & 1,0000 \\
\hline
\end{tabular}

ns e *: Não-significativo e significativo a $\alpha=5 \%$.

atividade ATPásica em raízes de milho colonizadas por FMAs (Quadro 2). A ativação das ATPases está de acordo com a idéia prevalecente da ativação do transporte bidirecional de metabólitos na interface simbiótica. Por outrolado, o estímulo da atividade pir ofosfatásica é inédito e o seu papel na associação micorrízica deve ser distinto daquele descrito para as ATPases, desde que não foi observada correlação significativa com a colonização micorrízica (Quadro 2). Neste sentido, é importante destacar que a ativação das enzimas que acoplam a hidrólise de PPi ao transporte de íons nas membranas de células de plantas tem sido relacionada com situações de estresse energético, caracterizadas pela depleção do ATP celular (Stitt, 1998). Assim, a máxima estimulação verificada aos 30 dias de colonização pode ser indicativo de que o PPi exerce um papel de destaque na energização das membranas durante o estádio que precede o estabel ecimento da colonização. Todavia, a confirmação desta hipótese requer estudos adicionais, incluindo a purificação de vesículas de tonoplasto e o estudo da cinética específica da $\mathrm{H}^{+}$ PPase durante o processo de mi corrização.

\section{CONCLUSÕES}

1. As atividades específicas (calculada com base na concentração de proteína total) das ATPases e pirofosfatases microssomais foram superiores nas raízes inoculadas com FMAs. Esta é a primeira descrição de uma ativação de pirofosfatases pela micorrização, evidenciando, desta forma, o envolvimento destes sistemas na adaptação energética necessária ao estabel ecimento da interação simbiótica FMA-plantas.

2. A espécie Gc mostrou-se mais efetiva na ativação das ATPases e pirofosfatases, o que se refletiu também numa maior taxa de colonização das plantas de milho e acúmulo de macronutrientes na parte aérea, em comparação com Gm. Estes dados revelam uma ativação diferencial espécie-específica destas enzimas, o que evidencia a possibilidade de serem elas usadas como marcador es bioquímicos de eficiência no processo de col onização mi corrízica.

\section{AGRADECIMENTOS}

À Coordenação de Pessoal de Nível Superior (CAPES) pela bolsa de PG à Alessandro Coutinho Ramos; ao Consel ho Nacional de Pesquisa (CNPq); à Fundação Carlos Chagas Filho de Amparo à Pesquisa do estado do Rio de J aneiro (FAPERJ ) eà International Foundation for Science (IFS), pelo suporte financeiro concedido à A.R. F açanha.

\section{LITE RATURA CITADA}

ALEXANDER, T.; MEIER, R.; TOTH, R. \& WEBER, H.C. Dynamics of arbuscule development and degeneration in mycorrhizas of Triticum-aestivum L. and Avena-sativa L. with reference to Zea mays L. New Phytol., 110:363-370, 1988. 
BAGO, B.; DONAIRE, J .P. \& AZCÓN-AGUILAR, C. ATPases activities of root from mycorrhizal sunflower (Helianthus annuus) and onion (Allium cepa) plants. New Phytol., 136:305-311, 1997.

BENABDELLAH, K.; AZCÓN-AGUILAR, C. \& FERROL, N. Plasma membrane ATPase and $\mathrm{H}^{+}$transport activities in microsomal membranes from mycorrhizal tomato roots. J . Exp. Bot., 50:1343-1349, 1999.

DE MICHELIS, M.I \& \& SPANSWICK, R.M. H+-pumping driven by vanadate sensitive ATPase in membrane vesicles from corn roots. Plant Physiol., 81:542-547, 1986.

EMPRESA BRASILEIRA DE PESQUISA AGROPECUÁRIA EMBRAPA. Manual de interpretação de análises de solo, plantas e fertilizantes. Brasília, 1997. 185p.

FAÇANHA, A.R. \& DE MEIS, L. Inhibition of maize root $\mathrm{H}^{+-}$ ATPase by fluoride and fluoroaluminate complexes. Plant Physiol., 108:241-246, 1995.

FAÇANHA, A.R. \& DE MEIS, L. Reversibility of $\mathrm{H}^{+}$-ATPase and $\mathrm{H}^{+}$-Pyrophosphatase in tonoplast vesicles from maize coleoptiles and seeds. Plant Physiol., 116:1487-1495, 1998.

FISKE, C.F . \& SUBBAROW, L. The colorimetric determination of phosphorus, J . Biol. Chem., 66:375-400, 1925.

GIANINAZZI-PEARSON, V.; ARNOULD, C.; OUFATTOLE, ARANGO M. \& GIANINAZZI, S. Differential activation of $\mathrm{H}^{+}$-ATPase genes by an arbuscular mycorrhizal fungus in root cells of transgenic tobacco. Planta, 211:609-613, 2000.

GIANINAZZI-PEARSON, V. Plant cell responses to arbuscular mycorrhizal fungi: getting to the roots of the symbiosis. Plant Cell., 8:1871-1883, 1996.

GIANINAZZI-PEARSON, V.; SMITH, S.E.; GIANINAZZI, S. \& SMITH, F.A. Enzymatic studies on the metabolism of vesicular-arbuscular mycorrhiza. $\mathrm{V}$. Is $\mathrm{H}^{+}$-ATPase a component of ATP-Hydrolysing enzyme activities in plantfungi interfaces? New Phytol., 117:61-74, 1991.

GIOVANNETTI, M. \& MOSSE, B. Evaluation of techniques for measuring vesicular arbuscular mycorrhizal infection in roots. New Phytol., 84:489-500, 1980.

GRAHAM, J.H. \& EISSENST, D.M. Host genotype and the formation and function of VA mycorrhizae. Plant Soil, 159:179-185, 1994.

GUTTENBERGER, M. Arbuscules of vesicular-arbuscular mycorrhizal fungi inhabit an acidic compartment within plant roots. Planta, 211:112-118, 2000.

J ACKSON, M.L. Soil chemical analysis. New J ersey, Prentice Hall, 1965. 489p.

KRAJINSKI, F.; HAUSE, B.; GIANINAZZI-PEARSON, V. \& FRANKEN, P. Mthal, a plasma membrane ${ }^{+}$-ATPasegene from Medicago truncatula, shows arbuscule-specific induced expression in mycorrhizal tissue. Plant Biol., 4:754-761, 2002.
LOWRY, O.H.; ROSEBROUGH, N.J .; FARR, A.L. \& RANDALL, R.J . Protein measurement with the olin phenol reagent. J . Biol. Chem., 193:265-275, 1951.

MALAVOLTA, E.; VITTI, G.C. \& OLIVEIRA, S.A. Avaliação do estado nutricional das plantas. Piracicaba, Associação Brasileira para Pesquisa da Potassa e do Fosfato, 1989. 201p.

MARX, C.; DEXHEIMER, J .; GIANINAZZI-PEARSON, V. \& GIANINAZZI, S. Enzymatic studies on the metabolism of vesicular-arbuscular mycorrhizas .4. Ultracytoenzymological evidence (ATPase) for active transfer processes in the hostarbuscule interface. New Phytol., 90:37-43, 1982.

MCARTHUR, D \& KNOWLES, N.R. Influence of vesiculararbuscular mycorrhizal fungi on the response of potato to Phosphorus Deficiency. Plant Physiol., 101:147-160, 1993.

MORSOMME, P. \& BOUTRY, M. The plant plasma membrane $\mathrm{H}^{+}$-ATPase: structure, function and regulation. Biophys. Biochim. Acta., 1465:1-16, 2000.

MURPHY, P.J .; LANGRIDGE, P. \& SMITH, S.E. Cloning plant genes differentially expressed during colonization of roots of Hordeum vulgare by the vesicular-arbuscular mycorrhizal fungus Glomus intraradices. New Phytol., 135:291-301, 1996.

PHILLIPS, J .M. \& HAYMAN, D.S. Improved procedures for clearing roots and staining parasitic and vesiculararbuscular mycorrhizal fungi for rapid assessment of infection. Trans. British Mycol. Soc., 55:158-160, 1970.

REA, P.A.; KIM, Y.; SARAFIAN, V.; POOLE, R.J .; DAVIES, J .M. $\&$ SANDERS, D. Vacuolar $\mathrm{H}^{+}$-translocating pyrophosphatases: a new category of ion translocase. Trends Biochem Sci., 17:348-353, 1992

SMITH, S.E. \& READ, D.J . Mycorrhizal symbiosis. 2.ed. London, Academic Press, 1997. 605p.

STITT, M. Pyrophosphate as an energy donor in the cytosol of plant cells: an enigmatic alternative to ATP. Bot. Acta, 111:167-175, 1998.

SZE, $\mathrm{H} . \mathrm{H}^{+}$- translocating ATPase: advances using membrane vesicles. Ann. Rev. Plant Physiol., 36:175-208, 1985.

SZE, H.; LI , X.\& PALMGREN, M.G. Energization of plant cell membranes by $\mathrm{H}^{+}$-Pumping ATPases: regulation and Biosynthesis. Plant Cell., 11:677-689, 1999.

TOTH, R.; DOANE, C.; BENNETT, E. \& ALEXANDER, T. Correlation between host-fungal surface-areas and percent colonization in VA mycorrhizae. Mycol., 82:519-522, 1990.

WILLIAMS, K.; PERCIVAL, F.; MERINO, J . \& MOONEY, H.A. Estimation of tissue construction cost from heat of combustion and organic nitrogen content. Plant Cell. Environ., 10:725-734, 1987. 
Alessandro Coutinho Ramos et al .

R. Bras. Ci. Solo, 29:207-213, 2005 